\title{
In Defense of the Lenient View
}

\author{
Peter Schaber ${ }^{1}$
}

Received: 22 September 2020 / Revised: 2 December 2020 / Accepted: 23 December 2020 /

Published online: 23 January 2021

(C) The Author(s) 2021

\begin{abstract}
This paper deals with the wrongness of having sex with someone without her valid consent. There are good reasons to think that deception about deal-breakers invalidate consent to sex and that acting without valid consent wrongs the consenter. Tom Dougherty argues that it is always seriously wrong to deceive another person into sex by deceiving her. We should on his view therefore reject the view that doing so is in certain cases only a minor wrong (this is what he calls "the lenient view"). It will be argued here that we should accept this view. I will argue against Dougherty that the lenient view does not presuppose an unacceptably moralistic view of sexuality. In addition, the lenient view can be defended by what I call the harm view of the wrongness of having sex without valid consent. If no or only mild harm is caused deceiving someone into sex is only a minor wrong.
\end{abstract}

Keywords Valid consent · Deceptive consent $\cdot$ Wronging others

\section{Introduction}

This paper deals with the wrongness of having sex with someone who has been deceived into consenting to it. Consider these two examples:

MARRIED WOMAN: Betty is flirting with Julia and communicates to her that she would not want to have sex with a married woman. Julia is married but lies to Betty that she is not married. Betty consents to having sex with Julia.

MUSICAL TASTE: John does not want to have sex with someone who likes the Beatles. He is flirting with Paul who happens to like the Beatles. Asked whether that is the case Paul lies to John. John consents to having sex with Paul.

Julia deceives Betty into consenting to having sex with her. Paul does the same with John. Various authors think that deception invalidates consent if - as in the two examples - the consenter is deceived about a deal breaker. A deal breaker should be

Peter Schaber

schaber@philos.uzh.ch

1 Department of Philosophy, University of Zurich, Zollikerstr. 117, 8008 Zurich, Switzerland 
understood as "any piece of information about the encounter to which a person's will is opposed, such that it would lead them to refrain from sex if they were aware of it" (Lazenby/Gabriel 2018: 622). Betty and John are thus both wronged because their consent to having sex with the other person is invalid.

I will assume that it is true that deception about deal breakers invalidates consent. And I will also assume that the consent-receiver wrongs the consenter if she has sex with her without having her valid consent. There are various reasons to hold the view that deception about a deal breaker invalidates consent.

Tom Dougherty thinks that this is the case because the deceived consenter does not intend to allow the other person to perform the act with a feature she does not know. He writes:

"In consenting, we intend to allow a restricted range of possibilities ... If we object to events in virtue of any feature of them, then they lie outside the restricted range of possibilities to which we are consenting" (Dougherty 2013: 736).

Danielle Bromwich and Joseph Millum argue that consent is invalidated by what is done to the consenter and not by the lack of knowledge. Betty's (and John's consent) is not valid on Bromwich and Millum's view because their consent is the result of a wronging. Julia and Paul exercise illegitimate control over Betty's and John's decision to consent, thereby invalidating their consent.

"(T)he invalidating potential of deception is properly located in what the recipient knows and ought to disclose, not what the profferer ought to understand" (Bromwich/ Millum 2018: 456).

Let us assume that for one of these reasons the view is true that deception about a deal breaker invalidates consent and that acting without valid consent is a wronging of the consenter. Thus what Julia does as well as what Paul does is wrong as a wronging of the consenter. But it seems that what Paul does with John is less wrong than what Julia does with Betty. And in addition it seems that what Paul does to John is only a minor wrong. Dougherty would reject the latter. On his view deceiving someone into consenting to having sex as well as having sex without valid sex are seriously wrong. We should reject what Dougherty calls "the lenient view" (LV):

(LV) "It is only a minor wrong to deceive another person into sex by misleading her or him about certain personal features such as natural hair color, occupation, or romantic love" (Dougherty 2013: 718).

The lenient view holds that it not just a minor wrong to deceive someone about such minor things; it is also a minor wrong to have sex with someone if the deception that leads to it is only a minor wrong. Dougherty thinks that it is seriously wrong to deceive someone into consenting to have sex and it seriously wrong to have sex with someone without having her valid consent. I will argue that the lenient view should be accepted.

The paper has four parts. The first part sets out Dougherty's argument that the lenient view presupposes an objectionable moralistic view of sexuality and explains why one might think that the harm view of the wrongness of having sex without valid consent is inadequate and thus not suited to defend the lenient view (2.). The second part shows first why the lenient view does not presuppose an "objectionably moralized conception of sex" (Dougherty 2013: 730). It then shows how the harm view of the 
wrongness of having sex without valid consent provides us with arguments speaking in favor of the lenient view (3.). The third part deals with the objection that all violations of the right to sexual autonomy are seriously wrong (4.). The fourth section concludes (5.).

\section{Against the Lenient View}

Dougherty thinks that the lenient view rests on - as he thinks - a false assumption that there are good and bad reasons to refuse to consent to have sex with others. He finds the view that there are, objectively, good and bad reasons not to have sex with someone an "unacceptably moralistic" view of sexuality. He writes: "One of the key achievements of waves of sexual liberation has been the promotion of a sexual pluralism that allows each individual to pursue his or her own conception of the sexual good" (Dougherty 2013: 730). So we cannot assume, say, that someone's character, or religion, or sexually transmitted infections are important features in sexual encounters with her, whereas her musical taste or hair color is not. People are free to determine what matters to them in matters of sex.

The lenient view faces an additional difficulty. One might think that it could be defended by what I will call the harm view of the wrongness of having sex with others without their valid consent. This is the view that the wrongness of having sex with someone without having her or his valid consent is determined by the harm (physical as well psychological) it causes. But this attempt of defending the lenient view cannot be successful if what Dougherty says about the harm explanation of the serious wrongness of having sex without valid consent is correct (Dougherty 2013: 726).

Let me explain. One might think that the deception and the sex it leads to are worse the stronger the deal breaker is; a deal breaker is stronger the more it matters to the consenter to be deceived about a certain deal breaker (Manson 2017: 420). ${ }^{1}$ Something that matters more to the consenter affects her in a different way. The deal breaker in Betty's case is presumably stronger than in John's case. It matters more to Betty not to have sex with a married person than it matters to John not to have sex with someone who does not like the Beatles. The stronger the deal-breaker is the more it is a set back to the interest of the consenter and the more harm is thus done to the consenter. This speaks in favor of the conclusion that what Paul does to John is less wrongful than what Julia does to Betty.

Alan Wertheimer argues that the wrongness of an act is a function of the harm suffered by the victim (Wertheimer 2003: 96). Thus one could argue that if no or only mild harm is done the deceived is not seriously wronged by being deceived into having sex. Nonconsensual sex is worse the more harm it causes. ${ }^{2}$ Dougherty thinks that this is correct. Nonconsensual sex is worse the more harm it causes. But this does on

\footnotetext{
${ }^{1}$ Neil Manson takes it that the stronger the deal breaker is the less voluntary the decision to consent.

2 On Wertheimer's view nonconsensual acts might cause different kinds of harm: a) objective or dignitary harm which he takes to be "a set-back to her rights-based interest in her bodily integrity or her sexual autonomy" (Wertheimer 2003: 97); b) physical injuries and enduring psychological harm "that impair the victim's ability to function" (Wertheimer 2003: 97); and finally c) psychological distress. And the seriousness of the wrong of nonconsensual sex is determined by the degree of harm they cause. Wertheimer's view on the seriousness of nonconsensual sex is the one I will defend in this paper.
} 
Dougherty's view not imply that nonconsensual sex that causes no harm is only a minor wrong, as the lenient view has it. He writes:

"The Harm explanation is inadequate when it comes to explaining the serious wrongness of sex with the unconscious or by egregious forms of deception. The reason why is simple: as John Gardner and Stephen Shute have noted, there need be no harm involved ... the victims ... do not suffer experiential harms" (Dougherty 2013: 726).

One might argue that sex with an unconscious person likely leads to harm (see Wertheimer 2003: 104-105). This might be true. But it could not be used to support the lenient view. This follows from what Dougherty says about cases of harmless unconsented sex. Having sex with an unconscious person without her valid consent is considered by us to be seriously wrong. But it is not considered to be seriously wrong because it causes harm to the unconscious person. It is considered to be seriously wrong even if it caused no harm (neither physical nor any psychological harm) at all. Dougherty writes:

"The sex itself may not be physically damaging. Since the victims are unaware of having nonconsensual sex, they do not suffer experiential harms... Nonetheless, even when entirely harmless, sex with the unconscious and sex by means of egregious form of deception are still seriously wrong" (Dougherty 2013: 726).

Harmless sex without valid consent is on Dougherty's view seriously wrong because it is done without valid consent. The harm view of the wrongness of unconsented sex cannot account for the serious wrongness of nonconsensual, harmless sex. This is one of the reasons why it - as Dougherty thinks - fails.

"The seriousness of the wrongs both of egregious deception and of sex with an unwilling unconscious person is explained by the fact that the victim did not validly consent to the sex" (Dougherty 2013: 724pp.).

\section{The Wrong-Making Properties of Having Nonconsensual Sex}

I will argue in this section a) that the lenient view does not presuppose - as Dougherty thinks - an objectionable moralistic view of sexuality, and b) that the harm view of the wrongness of having sex without valid consent provides us with a defense of the lenient view.

Let me start with supposedly false assumption that there are, objectively, good and bad reasons to refuse to consent to having sex with someone. The lenient view does not presuppose such moralism. The reason why some deceptions are only mildly wrong is not that there are universal objective facts to the effect that some features are bad reasons not to have sex. It is that individuals might refuse to have sex for what they subjectively consider to be weak reasons. John might consider the Beatles one of the 
most important things in his life. He might care very much about not having sex with someone who disdains them, and be devastated upon finding he had. In that case, it would be seriously wrong by Paul to pretend to love them, and deceive John into sex. But equally, John might refuse to have sex with disdainers of the Four Lads from Liverpool out of pure caprice - simply because he currently does not fancy, or is not in the mood, or wants to tease Paul a little. He might not really care about it at all, and feel only slightly baffled or bemused upon finding he did have such sex. In that case, it would still be wrong to deceive him. People should be able to determine with whom they have sex. But the wrong would be relatively mild.

In short, the lenient view fully respects the insights of sexual liberation. It does not presuppose a universal objective conception of the sexual good. The key point is that things can matter little to people themselves, even if they treat them as deal-breakers. And the less a deal-breaker matters to someone, the less seriously wrong it is to deceive them about it.

Let us now take a look at the harm view of the wrongness of unconsented sex and use in defense of the lenient view. I will assume that the musical taste case is an example of harmless sex and that the married woman case is an example of harmful sex. John is deceived about a weak deal breaker and the sex is wrong because it is done without valid consent. The married woman example on the other hand is a case of harmful sex. Betty is deceived about a strong deal breaker and having sex with Julia is not just done without her valid consent; it is also causing considerable psychological harm once Betty realizes what was going on in this case. Julia disregarded something that really matters to Betty. If harm adds to the seriousness of the wrongness of the act in question, the latter case is worse than the former. The deception is worse because the deal breaker is stronger and having nonconsensual sex is worse because harm has been inflicted upon the consenter. Dougherty agrees that the harm makes an act worse.

"The Harm explanation is particularly attractive with respect to coercive sex, which is typically conceived of as sex obtained by physical force or threats of physical harm" (Dougherty 2013: 725pp.).

The same applies, of course, to sex causing psychological harm. Harm makes the act worse. However, on Dougherty's view deceiving someone into consenting to having sex is always seriously wrong. What Paul does to John is thus seriously wrong even though less wrongful than what Julia does to Betty. But having sex without valid consent is seriously wrong.

Let us have a closer look at the two cases again: They have different wrong-making properties: What Paul does to John is wrong because John has not given his valid consent to the having sex with Paul. What Julia does to Betty is wrong because she acts without Betty's consent and causes her considerable psychological harm. The latter is part of the wrong-making property. The causing considerable harm contributes the wrongness of the act otherwise it would not be worse than an act of having harmless sex. Thus, we have the following wrong-making properties:

(1) Acting in a consent-requiring way without actually having valid consent

(2) Acting in a consent-requiring way without having valid consent causing considerable harm 
Property (1) is the wrong-making property of what Paul does to John. Property (2) is the wrong-making property of what Julia does to Betty. What Paul does is wrong due to the lack of valid consent. What Julia does is wrong because she acts without Betty's valid consent causing her considerable harm. An act that has the wrong-making property (2) is worse than an act that has the wrong-making property (1). What Paul does to John is on Dougherty's view less wrongful than what Julia does to Betty but still seriously wrong.

I think we should reject Dougherty's conclusion. (1) can also be the wrong-making property of nonsexual acts. Consider this: You take my umbrella without having my valid consent. You lie to me by telling me that you do not have one yourself. I would not have lent you my umbrella if I had known this. I lend you my umbrella. I was deceived about a dealbreaker. You wronged me by deceiving me into consenting to give you my umbrella. The deal breaker is a weak one, a very weak one because I actually do not care about the umbrella. If it is wrong to act without valid consent I have been wronged. No one would think that I have been seriously wronged. What you did was not okay but definitely nothing seriously wrong.

The act you performed is wrong due to the wrong-making property (1). It has thus the same wrong-making property as the act in the musical taste example. The property that makes an act wrong determines also the degree of the wrongness of an act. If two acts have the same wrong-making property they are equally wrong. Thus, if the umbrella case is not a case of a serious wronging the act musical taste is not either. They are thus both not seriously wrong. This follows from the fact that they have the same wrong-making property. And if we judge the umbrella case not to be an example of a serious wrong we have to say the same about the musical taste example. And because it would indeed be completely implausible to judge the umbrella case as an act of serious wrongdoing we can't judge the musical taste case as an example of such a serious wrongdoing.

Dougherty argues that we consider the case of having sex with an unconscious as seriously wrong. Thus one might argue that we would also consider the musical taste example as a case of seriously wronging the consenter. The given argument does not seem to succeed. However, I think it does.

Dougherty assumes that we judge having sex with the unconscious to be seriously wrong regardless of the possible harm it might cause (for instance, when the person becomes conscious again). But he is wrong on this point. It is not plausible to assume that sex with an unconscious person is a case of harmless sex. There is an account of why we think that it is seriously wrong to have sex with an unconscious person that is compatible with the harm explanation. There are two versions of this type of act: a) The victim becomes conscious again discovers what has been done to her she will unlikely not be harmed by the act. She will likely suffer from serious psychological harm as well as from a respect-based harm, that is the harm caused by the disregard the other person has shown, treating the victim as if she could treat her as she pleases. b) The victim remains unconscious and will never realize what was done to her. If we judge this as a serious wrong we do so because we think that the unconscious person is seriously harmed even if this does not cause experiential harm to her. Those who do so do not think that harm has to be experiential harm to be bad for the victim. They might be wrong on this point. ${ }^{3}$ However, it explains why they consider sex with an unconscious person to be seriously wrong.

\footnotetext{
${ }^{3}$ This is not something to be discussed in this paper.
} 
The act gets morally worse if it in addition causes harm. The more harm it causes the more seriously wrong it is. It is seriously wrong only if it causes considerable physical or psychological harm (or any other kind of harm). It is not seriously wrong if it causing no or only minor harm.

\section{An Objection}

One might object that the acts in the musical taste example and in the umbrella example have the same wrong-making properties but they are still not equally wrong. They differ in their wrongness due to the rights that are violated by the two acts. In the first case a right to sexual autonomy in the second case a property right has been violated. They are both violated due to the lack of consent. However, the violation of a right to sexual autonomy is seriously wrong, the violation of the property right is not a serious wrong. The difference is due to the importance these two rights have. And one could argue that violations of the right to sexual autonomy are always seriously wrong because our sexual autonomy is so important to us. And because it is so important any illegitimate interference with our sexual autonomy is seriously wrong.

Rights protect interests or the will of people and so does the right to sexual autonomy. ${ }^{4}$ It is the name of a bundle of rights such as the right to be able to decide with whom you have sex and how you have sex with another person, the right not to have sex with people you do not want to have sex with, the right to release another person from her duty not to have sex with you unless you consent, and finally the right not be deceived into consenting to have sex with another person. These rights protect various interests or wills. The right to control your consent protects, for instance, your interest in deciding yourself to consent or to refuse to consent. If you are deceived about a deal-breaker your control interest is set back by the deceiver. The stronger the deal-breaker is, the more the deal-breaker matters to you the more serious is the rights violation. The more important the interest is the more serious the wronging done to you by the other person.

The seriousness of violations of rights varies with the importance of the interests thwarted by them. The more important the interests are the more serious the violations are. This is why taking the umbrella without my valid consent is less wrongful than forcing me into handing over my dearly valued stamp collection. I think that the same applies to the violations of the right to sexual autonomy. Take the right not to be deceived into consenting to sex. You have an interest in controlling your decision to consent. Your interest is not satisfied if the consent-receiver controls you by deceiving you about a deal breaker. She wrongs you by doing so. Some deal breakers are stronger than others. And the deception is worse the stronger the deal breaker is. The absence or presence of some deal breaking condition is a stronger setback to people's interests than the absence or presence of other deal breaking conditions. And the unconsented act is worse the stronger the deal breaker is. To take our examples: Betty's deal breaker is arguably stronger than John's deal breaker for not having sex with others. Their right to control their decision to consent to sex which is part of their sexual autonomy is in both cases violated. However, what Julia does to Betty is worse than what Paul does to John.

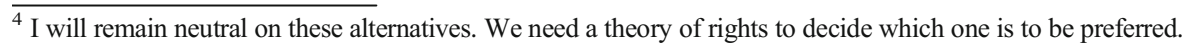


One might concede this and argue that deceiving someone into consenting to sex is seriously wrong as a violation of sexual autonomy. But the wrongness of a violation of a right corresponds to the importance of the interest or the will which is disregarded by the right violating act. This is why forcing me to hand over the highly valued stamp collection is seriously wrong and the taking of the umbrella without my valid consent is not seriously wrong. The two things matter to me in different ways, the former much more than the latter. Thus if deal breaker in the musical taste case does not harm John he is not seriously wronged even though his right to sexual autonomy has been violated. The violations of your right to sexual autonomy are the worse the more the interest or will at stake matters to you. And this is what the "lenient view" tells us. It is only a minor wrong to deceive someone into sex and to have sex with her if what is disregarded by these acts matters not much to the deceived.

\section{Conclusion}

Dougherty argues that deceiving another person into sex by misleading her about a deal breaker is always seriously wrong and that the lenient view according to which some of these acts are only a minor wrong should be rejected. It was argued that the lenient view does not presuppose an objectionably moralized conception of sexuality and that the wrongness of having sex without valid consent are determined by the harm they cause. If no or only mild harm is caused by acting accordingly only a minor wrong is done. Thus we should accept the lenient view.

Acknowledgements For helpful feedback and comments on an earlier draft of the paper I would like to thank Felix Koch, Stefan Riedener, and an anonymous referee of this journal.

Funding Open Access funding provided by Universität Zürich.

Open Access This article is licensed under a Creative Commons Attribution 4.0 International License, which permits use, sharing, adaptation, distribution and reproduction in any medium or format, as long as you give appropriate credit to the original author(s) and the source, provide a link to the Creative Commons licence, and indicate if changes were made. The images or other third party material in this article are included in the article's Creative Commons licence, unless indicated otherwise in a credit line to the material. If material is not included in the article's Creative Commons licence and your intended use is not permitted by statutory regulation or exceeds the permitted use, you will need to obtain permission directly from the copyright holder. To view a copy of this licence, visit http://creativecommons.org/licenses/by/4.0/.

\section{References}

Bromwich, D., \& Millum, J. (2018). Lies, control, and consent: A response to Dougherty and Manson. Ethics, $128,446-461$.

Dougherty, T. (2013). Sex, lies, and deception. Ethics, 123, 717-744.

Lazenby, H., \& Gabriel, I. (2018). Permissible secrets. The Philosophical Quarterly, 68, 265-285.

Manson, N. (2017). How not to think about the ethics of deceiving into sex. Ethics, 127, 415-429.

Wertheimer, A. (2003). Consent to sexual relations. Cambridge.

Publisher's Note Springer Nature remains neutral with regard to jurisdictional claims in published maps and institutional affiliations. 